DOI: https://doi.org/10.24297/jaa.v10i0.8392

\title{
Potential Influence of Climate on Ugandan Aquaculture
}

\author{
${ }^{1}$ Shamim Naigaga, ${ }^{2}$ Claude E Boyd, ${ }^{3}$ Joseph Molnar, ${ }^{4}$ Philippe Gaillard \\ 1, 3203 Comer Hall Auburn University, Auburn, 36849 AL USA \\ 2101 North College, E W Shell Fisheries Center, Auburn, 36830 AL USA \\ 221 Parker Hall Auburn University, Auburn, 36849 AL USA
}

shamimnaigaga@gmail.com, boydce1@auburn.edu, molnarjj@auburn.edu, prg0007@auburn.edu

\begin{abstract}
Climate defines the viability of an area for aquaculture at the macro-scale (extensive) level as it dictates water temperature and water quantity in a location that in turn affects fish productivity. Temperature and rainfall data from 1980 to 2016 were analyzed and compared among the different regions of Uganda (Central, Eastern, Northern, and Western) using the Seasonal Mann Kendall Times Series and the 12-month Standard Precipitation Index (SPI). These data were used in the computation of monthly water requirements of the different regions. A positive upward temperature trend for all regions except the Eastern region $(p=0.4222$, tau $b=0.027$ ) showed increase of aquaculture production the future. The 12-month SPI showed all regions having near-normal SPI (-0.99 to 0.99) but with the Central region having the highest SPI and the western region with the lowest SPI. The Central region had the lowest monthly water requirement compared to other regions, which was attributed to lower temperatures and lower evaporation rates compared to others. Overall, potential climate effects on aquaculture are not a major issue in the country if climate smart strategies are adopted.
\end{abstract}

Keywords: Climate variability, aquaculture, Uganda

\section{Introduction}

The World Meteorological Organization [1] defines climate as the measurement of the mean and variability of relevant quantities of certain variables (such as temperature, precipitation, or wind) over a period of 30 years or more. Climate defines the viability of an area for aquaculture at the macro-scale (extensive) level as it dictates water temperature and water quantity in a location [2,3] which in turn affects fish productivity [4].

Fish are poikilothermic with each species having a specific temperature range. Temperatures outside the optimum range cause poor growth, reproduction complications, and increases sensitivity to parasite and disease infestation [5]. Extended periods with the temperatures outside the optimal range for a species result in it being unsuitable for aquaculture at a location.

Boyd [6] states that aquaculture depends on a constant supply of water with the total volume of water used for aquaculture per unit production greater than for agricultural crops. All fresh water sources have been noted to depend on precipitation [4]. Yoo and Boyd [7] expressed the importance of precipitation excess and deficit in fisheries and aquaculture. Nicholson [8] puts Uganda among the countries with frequent occurrence of drought and plagued with floods which have devasting effects on livelihoods, mainly if both occur in the same year [9].

Droughts, floods, landslides, windstorms, and hailstorms also have been reported to contribute well over $70 \%$ of the natural disasters, destroying an average of 800,000 hectares of crops valued at $\$ 33$ million annually [10]. Such events could also have negative impacts on pond fish culture as well. Heavy precipitation excess can 
lead to large volumes of runoff containing suspended soil particles. The suspended matter increases pond turbidity, which in turn lowers light availability for primary production, and suspended particles smother benthic organisms and settle on fish eggs [5]. A precipitation deficit leads to an excessive decrease in pond water levels that causes crowding, destructs spawning areas and benthic food availability, favors the growth of pondweeds, and increases the concentration of dissolved substances $[7,5]$.

Even though Uganda has a tropical climate, fluctuations in minimum, maximum temperatures, and rainfall patterns can affect fish production. The way climate fluctuates yearly above or below a long-term average value is called climate variability [1]. In Uganda, climate variability is mainly the result of remote forcing by the El Niño Southern Oscillation (ENSO) near the equatorial Pacific Ocean where fluctuations of sea surface typically causing temperatures to alternate every few years between a warming phase (El Niño) and cooling periods (La Niña), with a neutral phase in between [11].

Local geographical factors like Lake Victoria and mountains ranges in Uganda also affect climate. The country's orientation, intensity of the Inter Tropical Convergence Zone (ITCZ), sub-tropical anticyclones, Indian ocean cyclones, monsoonal winds, sea-surface temperatures, and jet streams all shape Uganda's climate [12, 13].

Aquaculture in Uganda depends on rainfall, streams, and wells for water during production in outdoor ponds $[14,5]$. These water sources are all climate vulnerable. The vulnerability of these water resources is aggravated with increased population growth and fragmented land use in the country.

Several studies have been carried out on the effects of climate variability on agriculture and fisheries in Uganda. For example, Phillips and McIntyre [11] and Timmers [15] focused on livestock and crops, and Vianny et al. [16] and Musinguzi et al. [17] discussed climate variability effects on the capture fisheries sector. Although much general information is available on agroclimatology, there are few works on fisheries production. Szumiec [18] and Kapetsky [4] discussed the effects of climate on aquaculture, but they did not address the practical use of climate variability in aquaculture. The review [5] focused on the possible use of climate information in aquaculture, but this work was mostly about principles related to climate and aquaculture.

The present study was conducted to consider the practical use of climate variability information in the planning of aquaculture production cycles in Uganda. The specific objectives of this study were to 1) compare temperature regimes and rainfall patterns among different regions of Uganda, 2) determine temperature variations from long term mean, 3) compute precipitation deficits and surplus and 4) draw monthly aquaculture water requirement and required pond inflows for the different regions of Uganda.

\section{Methods}

Uganda is centered at $1.3733^{\circ} \mathrm{N}, 32.2903^{\circ} \mathrm{E}$ in East Africa. It has a tropical climate, with air temperature ranging from $16^{\circ} \mathrm{C}$ to $30^{\circ} \mathrm{C}$. The average altitude of the country is $1,100 \mathrm{~m}$ above sea level excluding the mountain ranges. The national average precipitation is $1,000 \mathrm{~mm}$ rainfall per annum. The wetter places of the country along the equator have a soil water surplus year-round. The two main rainfall regimes experienced in Uganda are bimodal in most part of the country and unimodal in the northern region. The bimodal regime is observed towards/near the equator with the first peak in April, for March-May (MAM) season, locally referred to as 'long rains' in East Africa. The second peak occurs in October, for September-November (SON) season. These seasons; MAM and SON seasons (wet seasons) are separated by two dry spells from June to August and December to February $[19,20]$.

The country was divided into four regions for this study; Western region, Central region, Eastern region, and Northern region using the administrative map of Uganda (Fig. 1). The Central and Western region has a bimodal rainfall while the Northern region has unimodal rainfall and Eastern region has intermediate rainfall $[21,11]$. 
Climate data consisting of precipitation and air temperature were obtained from the Uganda National Meteorological Authority for the years 1980 to 2016. Climate data were collected for the Gulu station to represent the Northern region, Jinja station for the Central region, Soroti for the Eastern region and Mbarara for the Western region. These districts were selected because they are known to give a better representation of the Ugandan climate [22]. Means, minimum and maximum of temperatures, annual rainfall totals, and evapotranspiration were computed and compared among the different regions using ANOVA test using Statistical Analysis System (9.4 version).

The Seasonal Mann Kendall time series was used to test the monotonic trend in the temperature data. The presence of seasonality implies that the data have different distributions for different seasons (in this case months of the year). The Seasonal Mann Kendall test is a nonparametric (distribution-free) method proposed by Hirsch et al. [23] for use with 12 months. It can be used when there are missing data and data that has less than one or more limits of detection (LD). The null hypothesis was that there is no monotonic trend over time while the alternative hypothesis was that for one or more months there is an upward or downward monotonic trend over time. Sen's slope was used to give the strength of the trend.

Nile tilapia and African catfish are the main aquaculture species in the country $[14,24)$. Mean temperatures were further compared to the optimum range of African catfish and Nile tilapia of $26-32{ }^{\circ} \mathrm{C}$ [14]. Deviations from the long-term mean were also computed to visualize how the temperature fluctuates over the years, and these were standardized to allow comparison among the regions [25].

Monthly rainfall totals were summed for each year to obtain annual rainfall totals, and later used in calculating standardized precipitation index (SPI) as precipitation deficit and excess is more important than precipitation alone in aquaculture $[26,7]$. The SPI was also noted to be more suitable for monitoring rainfall patterns, especially droughts than other indices $[27,28]$.

The SPI was designed to quantify the precipitation deficit for multiple timescales, which reflect the impact of drought on the availability of the different water resources, characterizing both wet and dry years. Since it is standardized, it allows comparisons between different locations [28]. The 12-month SPI reflects long-term precipitation patterns and is tied to stream flows, reservoir levels, and even groundwater levels at longer timescales [30]. The SPI of the different regions were further compared.

Potential evapotranspiration (PET) was computed using the Blaney-Criddle model adopted from Ssegane, et al. [31] as shown below;

PET $=p\left[\left(0.46 \times T_{m}+8\right)\right]$, where $p$ depends on the month and the latitude of a location and a value of $p=0.27$ was deemed appropriate for all months for Uganda because it lies at the equator; $T_{m}=$ the mean temperature. The mean temperature was calculated by the usual method of averaging the maximum and minimum temperatures in the region.

Water budgets for the different regions were determined by subtracting the outflows (evapotranspiration and seepage) from the inflows (precipitation) [32]. This allows water requirement (WR) to be estimated for production cycles for the different regions as shown below;

$W R=[(P \times 1.1)-(P E T \times 1.3)-S]$, where $P$ is mean monthly precipitation, $P E T$ is monthly potential evapotranspiration, $S$ is mean seepage of $80 \mathrm{~mm} / \mathrm{month}$ and the factors 1.1 and 1.3 were to compensate the amount of rain that drain into the pond through the pond dikes and the higher evaporation from free surfaces for small open ponds respectively.

Furthermore, estimated monthly required inflows in liters per minute per acre farm were calculated with assumptions adopted from Yoo and Boyd [7]. 


\section{Results and Discussion}

Mean temperature, mean annual rainfall, and mean potential evapotranspiration were higher for the Northern and Eastern region than the Central and Western region (Table 1). This agreed with an earlier climatic assessment by Phillips and McIntyre [11]. Higher mean rainfall for the Eastern region can be attributed to Lakes Victoria and Kyoga and mountain Elgon's influence [33]. Higher mean annual rainfall in the Northern region can be attributed to the hilly peaks of Ngeta, Moru, and Kilak which enhance precipitation in the region by orographic lifting, especially when there is a surge of the moist Congo air mass converging with the prevailing synoptic easterlies during July-August [34]. The mean evapotranspiration rates were highest in the Eastern region, then the Northern region, followed by the Central region and least in the Western region.

There were significant differences in the mean temperature $(F=836.06, p<0.0001$, $d f=3$, at $p=0.05)$, mean annual rainfall $(F=41.66, p<0.0001, d f=3$, at $p=0.05)$, and mean potential evapotranspiration $(F=11.43, p$ $<0.0001$, $\mathrm{df}=3$, at $\mathrm{p}=0.05$ ) among the regions (Table 1). The post-hoc multiple comparison test by Tukey's Studentized Range (HSD) showed mean temperatures, and mean potential evapotranspiration were different among regions. Mean annual rainfall was also different among regions apart from that of Eastern and Central region, which were similar (Table 1). This was in line with data reported by Nicholson [12] where he classified Central and Eastern regions in the equatorial rainfall region.

Linkages between temperature and optimum temperature range for catfish and tilapia showed that all regions had a mean temperature below the optimum range of $26^{\circ} \mathrm{C}$ to $32^{\circ} \mathrm{C}$ [35] apart from the Eastern region over the years (Fig. 2). Although the temperatures were out of the optimum range for the culture of African catfish and Nile tilapia, they were not outside the range tolerated by these species, which has a lower limit of $20^{\circ} \mathrm{C}$ $[35,14]$ apart for the Western region (Fig. 2). The lower temperature in the Western region possibly could allow a culture of cool-water fish species such as trout in some areas.

Seasonal Mann Kendall output showed a positive increasing trend in temperatures among the regions apart from the Eastern region (Table 2). This implies increasing temperatures in those regions which will favor aquaculture production in the future. The strength of the slope was weak for the regions that had the trend as the temperature varied between $0.002{ }^{\circ} \mathrm{C} / \mathrm{yr}$. for the Eastern region to $0.058{ }^{\circ} \mathrm{C} / \mathrm{yr}$. for the Northern region (Table 2).

Deviations from the long-term mean (Fig. 3) showed that there were high temperature fluctuations in the Western regions than other regions over the years. However, the fluctuations were within $6{ }^{\circ} \mathrm{C}$ for all regions, which was noted to be suitable for young fish but not larger fish [35]. Furthermore, Szumiec [18] observed that a difference of $1^{\circ} \mathrm{C}$ from the seasonal mean temperature to correspond to a difference of $1000 \mathrm{~kg} / \mathrm{ha}$ in carp production which indicates a decreased performance for production facilities.

The 12-month SPI showed a rainfall deficit in the Northern and Western Region but are classified as near normal (-0.99 to 0.99), according to McKee et al. [29] (Table 2). Eastern region and Central region also were near normal although Central region had the highest SPI (Table 2). The classifications were made, according to McKee et al. [29]. The negative SPI values in the Northern and Western region indicate the need for strategies for storing water during their rainy seasons for use in the dry season. Over the years, all regions generally fell within -1.5 to $1.5 \mathrm{SPI}$ that is between moderately dry to moderately wet (Fig. 4). There were more flood events than drought events over the years in all regions. The climatic events coincided with the years noted as severe to extreme floods/drought [36]. The frequency of flood events was more pronounced in the Eastern region (that is every five years) than other regions. This could be due to the influence of Lakes Victoria and Kyoga and Mountain Elgon coupled with the El-Nino.

The Central region had the least water requirement compared to other regions (Fig. 5), which were in line with the mean SPI results. This could be the result of the lower potential evapotranspiration and mean temperatures in the Central region compared to other regions. Therefore, a year-round production cycle is possible in the Central region that would allow for stocking ponds at different times. However, it may be 
optimal when pond preparation is in December-February where pond bottom soils dry out, and fertilizer application can be made in the dry season without nutrient leaching problems.

The Eastern and Western regions had a similar possible production cycle where pond preparation or fish harvest could be in June-July or December-February. This is advantageous as pond refilling would be easier during the rainy season that follows, and it also presents a competitive market and high-profit margin as other poultry products are less available in the local markets during the dry season [37].

In the north, a single production cycle is possible with pond preparation in March and fish harvest in December unless water harvesting is done to store water for use during the dry months. Fish harvest in December would be advantageous to the Northern region as fish is a delicacy sought at this time of the year [38]. Harvest during the holiday and vacation season will increase prices for farmers.

The monthly required inflows for levee ponds showed that all regions required water during the DecemberFebruary period, which is the longest dry season (Table 3). However, the Western and the Northern region had the highest water requirements of the four regions. The results corresponded with studies conducted by Orlove et al. [39] and Funk [40].

The high-water requirement in the Western region can be attributed to the lee shadow effect caused by the Rwenzori mountain; hence, winds warm-up, descending in the region and suppressing precipitation [34,39]. The high-water requirement in the northern zone can be attributed to the region's unimodal rainfall pattern, thus most part of the year, it is dry. The northern region is also far away from the influence of the moisture transport from Lake Victoria resulting in drier climate. Furthermore, the northern region is generally a plateau which does not significantly disrupt moist winds hence moderate rains. This coupled with the drought events that have occurred yearly since 2008, and especially during July-August when the Northern region is expected to get most rains [9].

Overall, the water requirement in all regions was within 2000 to $1 \mathrm{~mm}$, which was classified as moderately suitable for ponds by Aguilar-Manjarrez and Nath [32].

Considering all factors, the Central region had the most favorable climate for aquaculture production. Nevertheless, all regions are suitable for aquaculture production provided water harvesting strategies are adopted for storing water during the dry periods.

\section{Conclusions}

The temperature was sometimes out of the optimum range in all regions, but the temperature range nonetheless would allow fish production. The Central region was considered most favorable among all regions for fish production. However, all areas were noted to be suitable for fish culture, provided water harvesting techniques were employed during the dry period.

Overall, potential climate effects on aquaculture are not that significant in the country if the right strategies are adopted that is; water harvesting during the drier periods and planning of the fish production cycle so as the period of water deficit coincide with the fish harvest or pond preparation.

The effective use of climate forecasts in aquaculture will depend on the success of extension workers and nongovernment organizations in sensitizing farmers on the implications of climate on fish production. Also, critical to the success of the implementation of the fish culture climate-smart strategies will be the timely provision to farmers of inputs, such as fertilizers and fish fingerlings by the non-government organizations and the government. 


\section{Data Availability}

Data will be available on the Harvard dataverse, and it could be assessed using the title of the manuscript.

\section{Conflicts of Interest}

No conflicts exist. Submitting authors are responsible for co-authors declaring their interests.

\section{Funding Statement}

This research was funded by USAID-AquaFish Innovation lab Project.

\section{Acknowledgement}

We are indebted to USAID-AquaFish Innovation lab Project for their financial support. We thank Mr. Deus Bamanya and the Uganda Meteorology Authority for their logistic support during data acquisition.

\section{Literature Cited}

1. WMO. 2017. CCI FAQs | WMO. Retrieved December 6, 2017, from http://www.wmo.int/pages/prog/wcp/ccl/faqs.php.

2. Coche, A. G. 1994. Aquaculture development and research in sub-Saharan Africa: National Reviews. FAO, Rome, Italy Aguilar-Manjarrez, J. and S. S. Nath. 1998. A strategic reassessment of fish farming potential in Africa. CIFA Technical paper 32. FAO, Rome, Italy.

3. Kaspersky, J. M., and S. S. Nath. 1997. A strategic assessment of the potential for freshwater fish farming in Latin America. FAO, Rome, Italy.

4. Kapetsky, J. M., 2000. Present applications and future needs of meteorological and climatological data in inland fisheries and aquaculture. Agricultural and Forest Meteorology 103:109-117.

5. Boyd, C.E., and Pine, H.J., 2010. Application of agrometeorology to aquaculture and fisheries, In Guide to Agricultural Meteorological Practices (GAMP). WMO-No. 134, Geneva, Switzerland.

6. Boyd, C. E., 2006. Management of bottom soil condition and pondwater effluent quality. Pages 449-467 in C. E. Lim and C. E.Webster, editors. Tilapia: biology, culture, and nutrition. The Hawort Press, Binghamton, New York, USA.

7. Yoo, K. H., and C. E. Boyd. 1994. Hydrology and Water Supply for Pond Aquaculture. Chapman and Hall, New York, USA Azaza, M. S., M. Legendre, M. M. Kraiem, and E. Baras, 2010. Size-dependent effects of daily thermal fluctuations on the growth and size heterogeneity of Nile tilapia Oreochromis niloticus. Journal of Fish Biology 76:669-683.

8. Nicholson, S. E., 2014. A detailed look at the recent drought situation in the Greater Horn of Africa. Journal of Arid Environments 103:71-79.

9. Nicholson Sharon E. 2015. An analysis of recent rainfall conditions in eastern Africa. International Journal of Climatology 36:526-532.

10. World Water Assessment Programme (United Nations Education, Science, and Cultural Organization). 2006. Water: a shared responsibility (No. 2). Case study: Uganda. UN-HABITAT. 
11. Phillips, J. and B. McIntyre. 2000. ENSO and interannual rainfall variability in Uganda: implications for agricultural management. International Journal of Climatology 20:171-182.

12. Nicholson, S. E., 2017. Climate and climatic variability of rainfall over eastern Africa. Reviews of Geophysics 55: 590-635.

13. Ogallo, L. J., 1988. Relationships between seasonal rainfall in East Africa and the Southern Oscillation. Journal of Climatology 8:31-43.

14. Isyagi, N., G. Atukunda, L. Aliguma, M. Ssebisubi, J. Walakira, G. Kubiriza, and E. Mbulameri. 2009. Assessment of national aquaculture policies and programmes in Uganda. Retrieved from https://www.cabdirect.org/cabdirect/abstract/20006802063.

15. Timmers, B., 2012. Impacts of climate change and variability on fish value chains in Uganda Retrieved September 28, 2017, from http://www.worldfishcenter.org/resource_centre/WF_3139.pdf

16. Natungoza, V., R. Ogutu-Ohwayo, J. Efitre, F. Muyodi, D. Mbabazi, M. Olukotum, S. Naigaga, and S. Namboowa. 2015. The responses of Nile tilapia Oreochromis niloticus (Linnaeus, 1758) in Lake Wamala (Uganda) to changing climatic conditions. Lakes \& Reservoirs: Research and Management 20:101-119.

17. Musinguzi, L., J. Efitre, K. Odongkara, R. Ogutu-Ohwayo, F. Muyodi, V. Natugonza, M. Olokotum, S. Namboowa, and S. Naigaga. 2016. Fishers' perceptions of climate change impacts on their livelihoods and adaptation strategies in environmental change hotspots: a case of Lake Wamala. Uganda. Environment, Development, and Sustainability 18:1255-1273.

18. Szumiec, M. A., 1983. Meteorology in the service of limnology and aquaculture. Polish Archives of Hydrobiology, Fish Culture Experimental Station-Golysz, Chybie

19. Mutemi, J.N. 2003: Climate anomalies over eastern Africa associated with various ENSO evolution phases. Ph.D. Thesis, University of Nairobi, Kenya.

20. Okoola, R.E. 1996: Space-Time characteristics of the ITCZ over Equatorial East Africa during anomalous rainfall years. Ph.D. Thesis, University of Nairobi.

21. Ogallo, L. J., 1989. The spatial and temporal patterns of the East African seasonal rainfall and derived from principal component analysis. International Journal of Climatology 9:145-161.

22. Komutunga, T. E., 2005. Optimum cropping calendar derived for rain-fed agriculture in Uganda using rainfall data. Ph.D. thesis. University of Nairobi, Nairobi, Kenya

23. Hirsch, R. M., J. R. Slack, and R. A. Smith.1982. Techniques of trend analysis for monthly water quality data. Water Resources Research 18:107-121.

24. Rutaisire, J., 2007. FAO Fisheries and Aquaculture Department - Study and analysis of feeds and fertilizers for sustainable aquaculture development. Retrieved September 28, 2017, from http://www.fao.org/docrep/011/a1444e/a1444e00.htm

25. Fathauer, T., 2011. A glimpse into a changing climate: New 1981-2010 climate normals take effect. Weatherwise 64: 34-36.

26. Boyd, C. E., and C. S. Tucker. 1998. Pond Aquaculture Water Quality Management. Kluwer, Massachusetts, USA. 
27. Hayes, M. J., M. D. Svoboda, D. A. Wilhite, and O. V. Vanyarkho.1999. Monitoring the 1996 drought using the standardized precipitation index. Bulletin of the American Meteorological Society 80:429-438.

28. Ntale, H. K., and T. Y. Gan. 2003. Drought indices and their application to East Africa. International Journal of Climatology 23:1335-1357.

29. McKee, T. B., N. J. Doesken, and J. Kleist. 1993. The relationship of drought frequency and duration to time scales. In Proceedings of the 8th Conference on Applied Climatology17:179-183

30. WMO. 2012. Standardized precipitation index user guide.: World Meteorological Organization, Geneva, Switzerland.

31. Ssegane, H., E. W. Tollner, and K. Veverica. 2012. Geospatial Modeling of Site Suitability for Pond-Based Tilapia and Clarias Farming in Uganda. Journal of Applied Aquaculture 24:147-169.

32. Aguilar-Manjarrez, J., and S. S. Nath. 1998. A strategic reassessment of fish farming potential in Africa. CIFA Technical paper 32. FAO, Rome, Italy.

33. Sun, X., Xie, L., Semazzi, F., and Liu, B. 2015. Effect of lake surface temperature on the spatial distribution and intensity of the precipitation over the Lake Victoria basin. Monthly Weather Review, 143: 1179-1192.

34. Basalirwa, C. P. K., 1995. Delineation of Uganda into climatological rainfall zones using the method of principal component analysis. International Journal of Climatology 15:1161-1177.

35. Azaza, M. S., Legendre, M., Kraiem, M. M., Baras, E., 2010. Size-dependent effects of daily thermal fluctuations on the growth and size heterogeneity of Nile tilapia Oreochromis niloticus. Journal of Fish Biology 76: 669-683.

36. Ogwang, B. A., T. Guirong, and C. Haishan. 2012. Diagnosis of September-November drought and the associated circulation anomalies over Uganda. Pakistan Journal of Meteorology 9:11-24.

37. Helgi, G., M. Ssebisubi, and K. Ögmundur. 2012. The value chain of farmed African catfish in Uganda. Proceedings of the Sixteenth Biennial Conference of the International Institute of Fisheries Economics and Trade, July 16-20, Dar es Salaam, Tanzania.

38. Jagger, P., and J. Pender. 2001. Markets, marketing, and production issues for aquaculture in East Africa: the case of Uganda. Naga, the ICLARM Quarterly 24:42-51.

39. Orlove, B., C. Roncoli, M. Kabugo, and A. Majugu. 2010. Indigenous climate knowledge in southern Uganda: the multiple components of a dynamic regional system. Climatic Change 100: 243-265

40. Funk, C., J. Rowland, G. Eilerts, L. White, T. E. Martin, and J. L. Maron. 2012. A climate trend analysis of Uganda. US Geological Survey Fact Sheet 3062.

Table 1. Mean temperature, maximum, minimum temperatures, and annual mean rainfall for years 1980 to 2016 in the different regions. Means are tested for difference by Tukey's Studentized Range (HSD) test; homogeneity of variances was tested by F-statistic. Means indicated by the same letter in a column do not differ (P-value $=0.05)$ according to HSD test.

\begin{tabular}{lllll}
\hline Region & Central & Eastern & Northern & Western \\
\hline Mean Temperature $(\stackrel{\circ}{C})$ & $22.66^{\mathrm{a}}$ & $24.94^{\mathrm{b}}$ & $24.07^{\mathrm{c}}$ & $21.09^{\mathrm{d}}$
\end{tabular}




\begin{tabular}{|c|c|c|c|c|c|}
\hline Minimum Temperature $(\stackrel{\circ}{C})$ & 17.80 & 22.60 & & 19.90 & 19.30 \\
\hline Maximum Temperature $(\stackrel{\circ}{C})$ & 28.90 & 34.70 & & 28.30 & 26.20 \\
\hline Annual mean Rainfall (mm) & $1248.0 \pm 284.39^{a}$ & $\begin{array}{l}1335.7 \\
210.28^{\mathrm{a}}\end{array}$ & \pm & $1476.0 \pm 174.30^{b}$ & $921.5 \pm 203.16^{c}$ \\
\hline $\begin{array}{l}\text { Mean Potential Evapotranspiration } \\
\text { (mm/month) }\end{array}$ & $151.2 \pm 4.17^{\mathrm{a}}$ & $160.0 \pm 4.86^{b c}$ & & $156.6 \pm 4.80^{\mathrm{ac}}$ & $145.3 \pm 3.94^{b}$ \\
\hline
\end{tabular}

Table 2. Seasonal Mann Kendall output and Mean SPI for the different regions

\begin{tabular}{|c|c|c|c|c|}
\hline Region & Central & Eastern & Northern & Western \\
\hline Tau b & 0.244 & 0.027 & 0.595 & 0.468 \\
\hline P-value & $<0.0001$ & 0.4222 & $<0.0001$ & $<0.0001$ \\
\hline Sen's slope & 0.015 & 0.002 & 0.058 & 0.038 \\
\hline Risk (\%) & 0.01 & 43.97 & 0.01 & 0.05 \\
\hline Mean SPI & 0.1225 & 0.0000 & -0.0003 & -0.0005 \\
\hline
\end{tabular}

Table 3. Monthly water requirement (inflows) in liters per minute (Ipm)/ acre for levee ponds

\begin{tabular}{lllll}
\hline Region & Northern & Central & Western & Eastern \\
\hline Jan & 5.91 & 3.22 & 0.00 & 3.48 \\
Feb & 5.34 & 4.09 & 0.00 & 3.14 \\
Mar & 0.08 & 0.00 & 0.00 & 0.00 \\
Apr & 0.00 & 0.00 & 0.00 & 0.00 \\
May & 0.00 & 0.00 & 0.00 & 0.00 \\
Jun & 0.00 & 3.44 & 0.00 & 0.00 \\
Jul & 0.00 & 3.41 & 0.72 & 0.00 \\
Aug & 0.00 & 0.30 & 0.00 & 0.00 \\
Sep & 0.00 & 0.00 & 0.00 & 0.00 \\
\hline
\end{tabular}




\begin{tabular}{llccc}
\hline Oct & 0.00 & 0.00 & 0.00 & 0.00 \\
Nov & 0.00 & 0.00 & 0.00 & 0.00 \\
Dec & 3.82 & 1.17 & 0.00 & 2.57
\end{tabular}
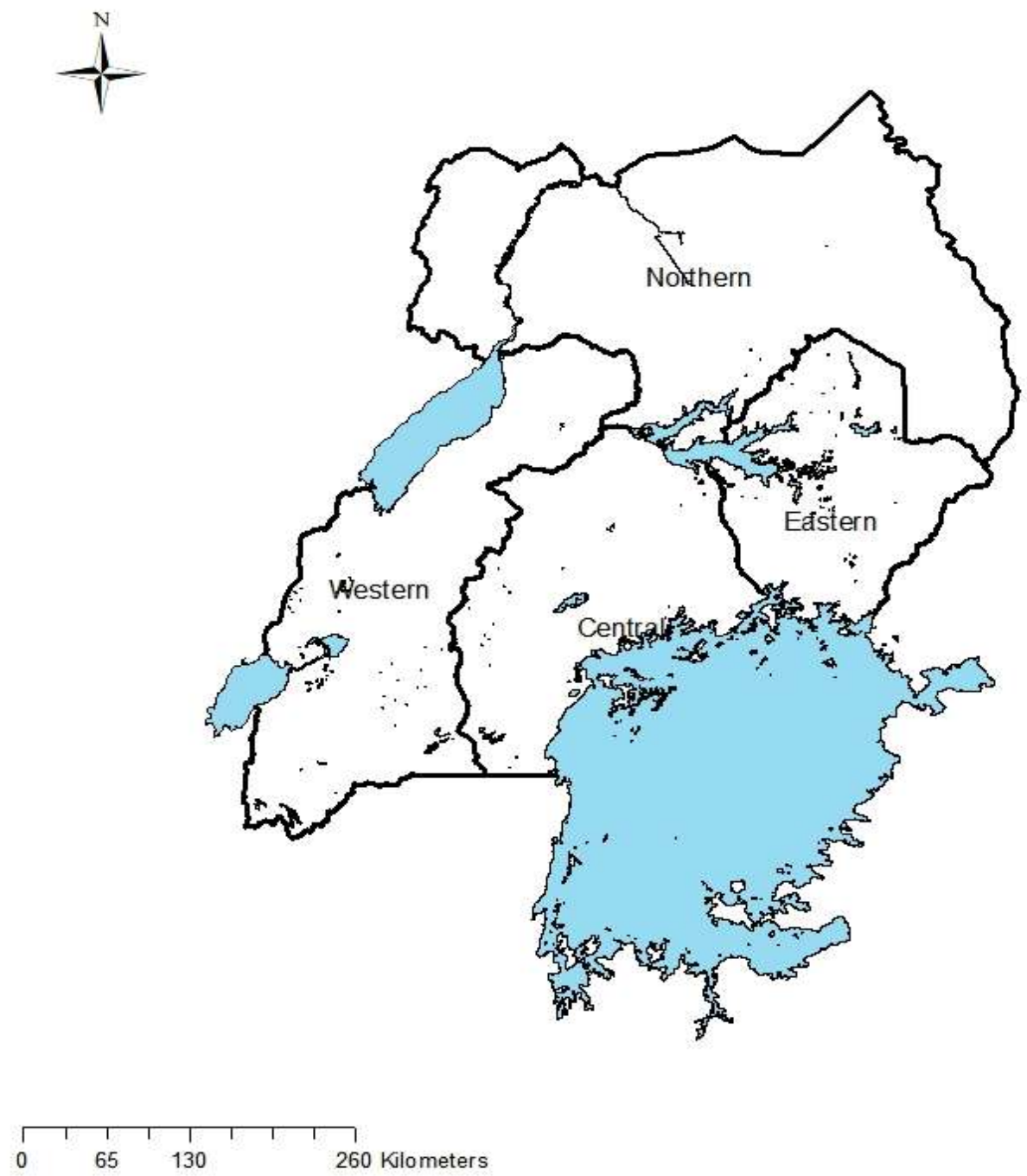

Figure 1. Administrative map of Uganda showing the different regions 


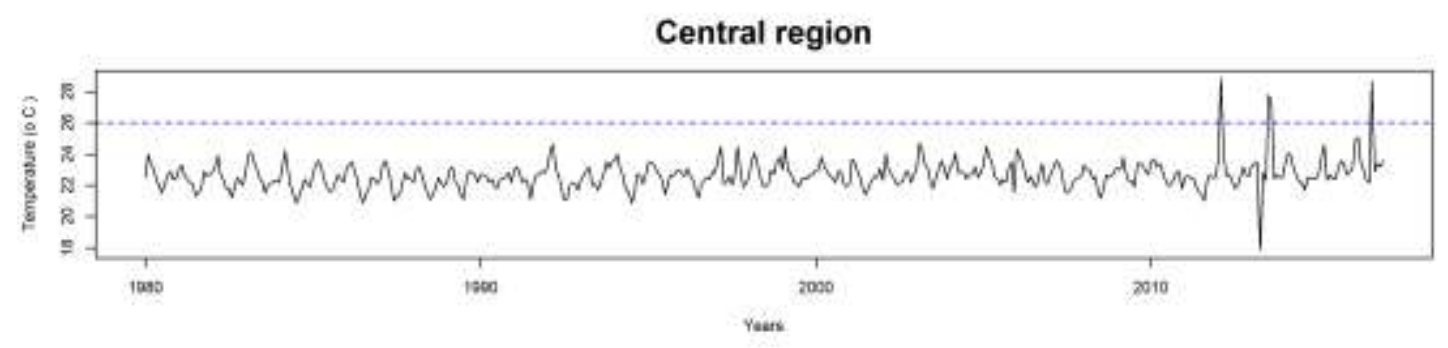

Eastern region

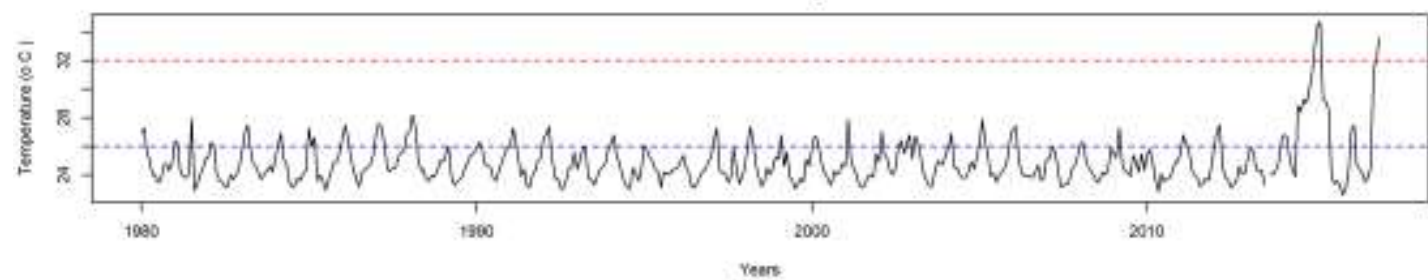

Northern region

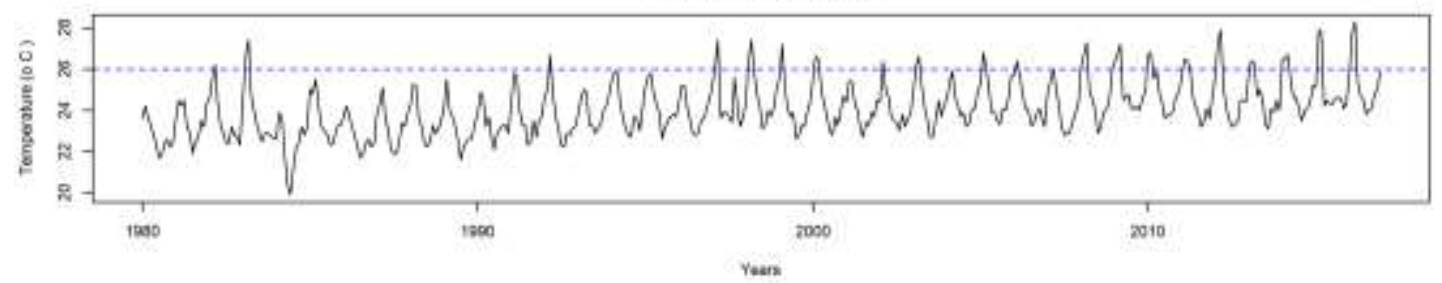

Western region

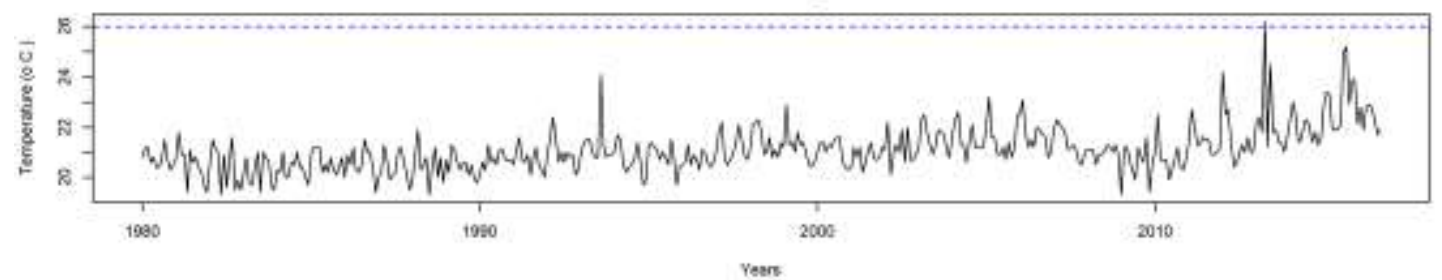

Figure 2. Mean Temperature for different regions for period 1980-2016 and how they relate with the optimum temperature range for culture of Nile tilapia and African catfish $\left(26-32{ }^{\circ} \mathrm{C}\right)$ 


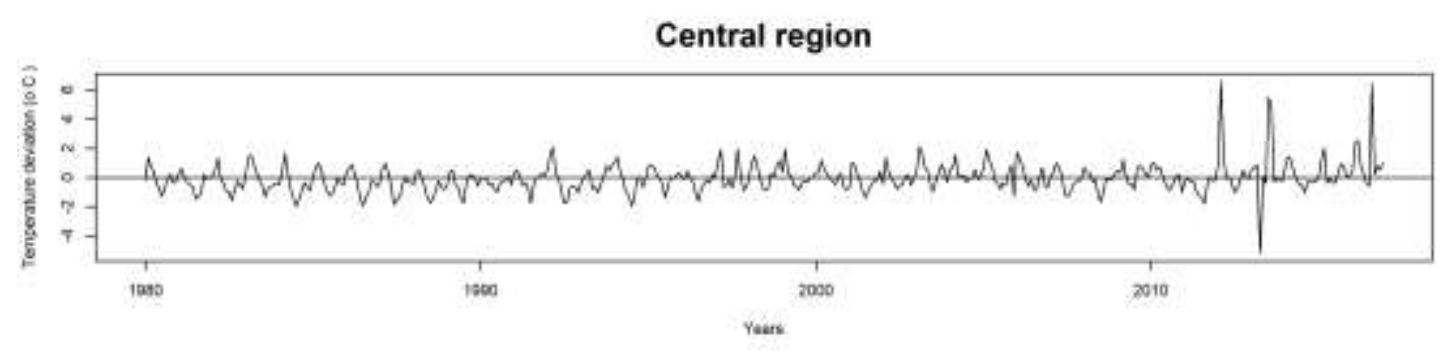

Eastern region

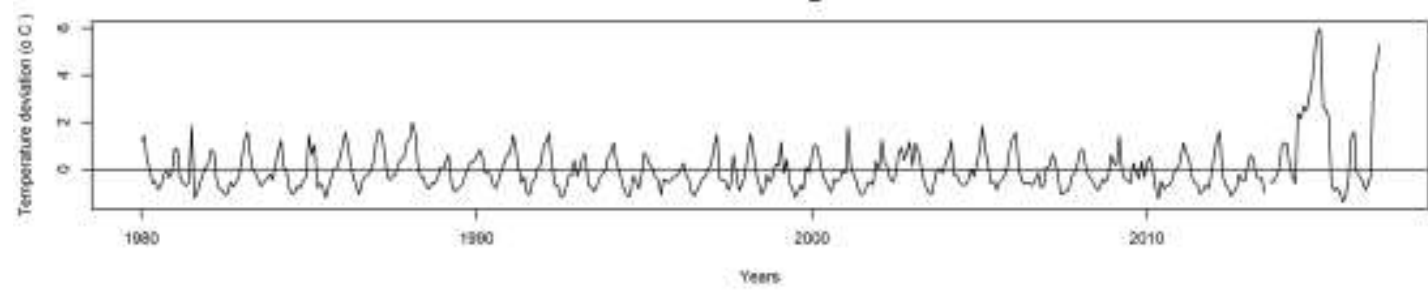

Northern region

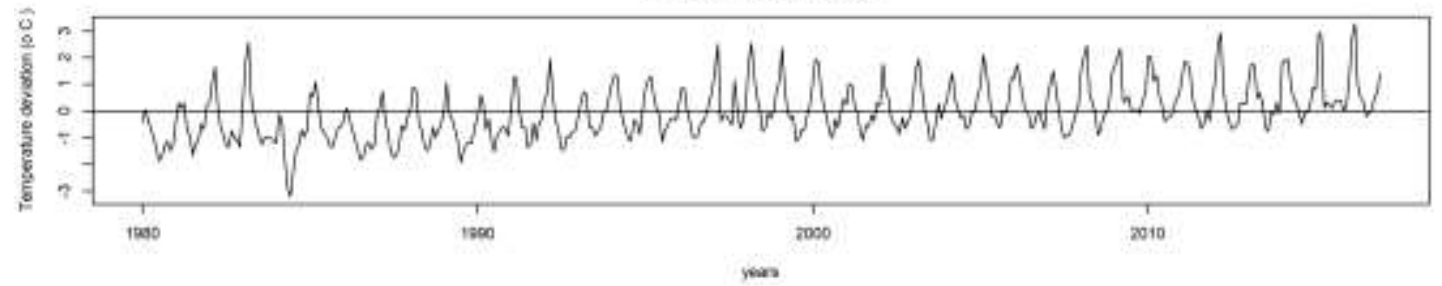

Western region

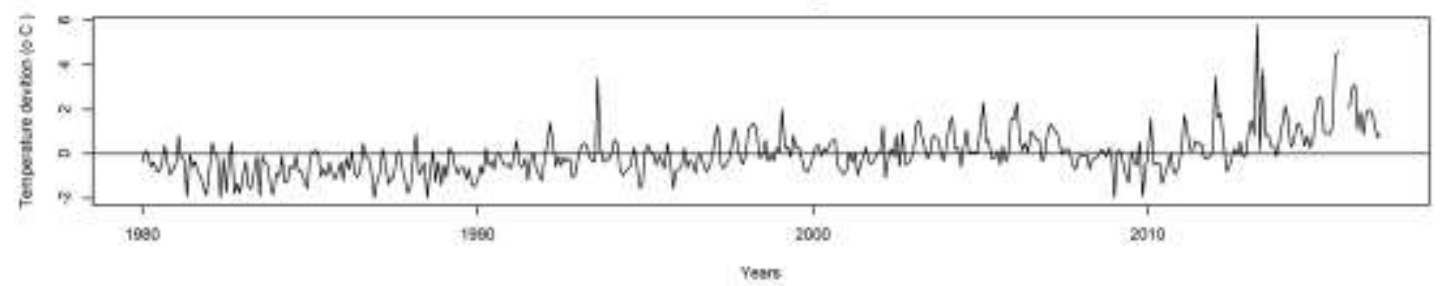

Figure 3. Temperature deviations from the long term mean for the different regions for a period 1980-2016 

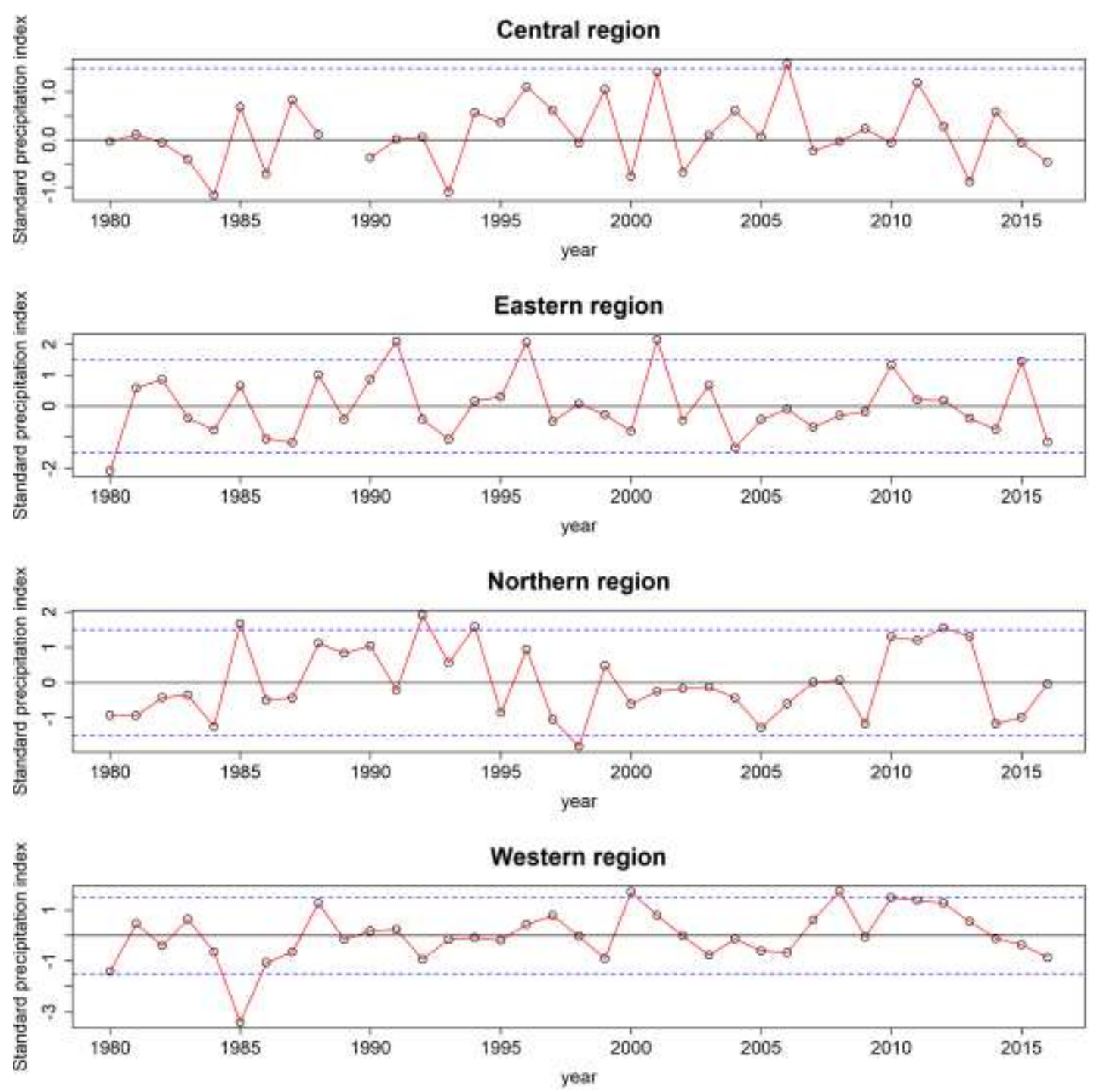

Figure 4. 12-month Standard precipitation index for the different regions for a period of 1980-2016 

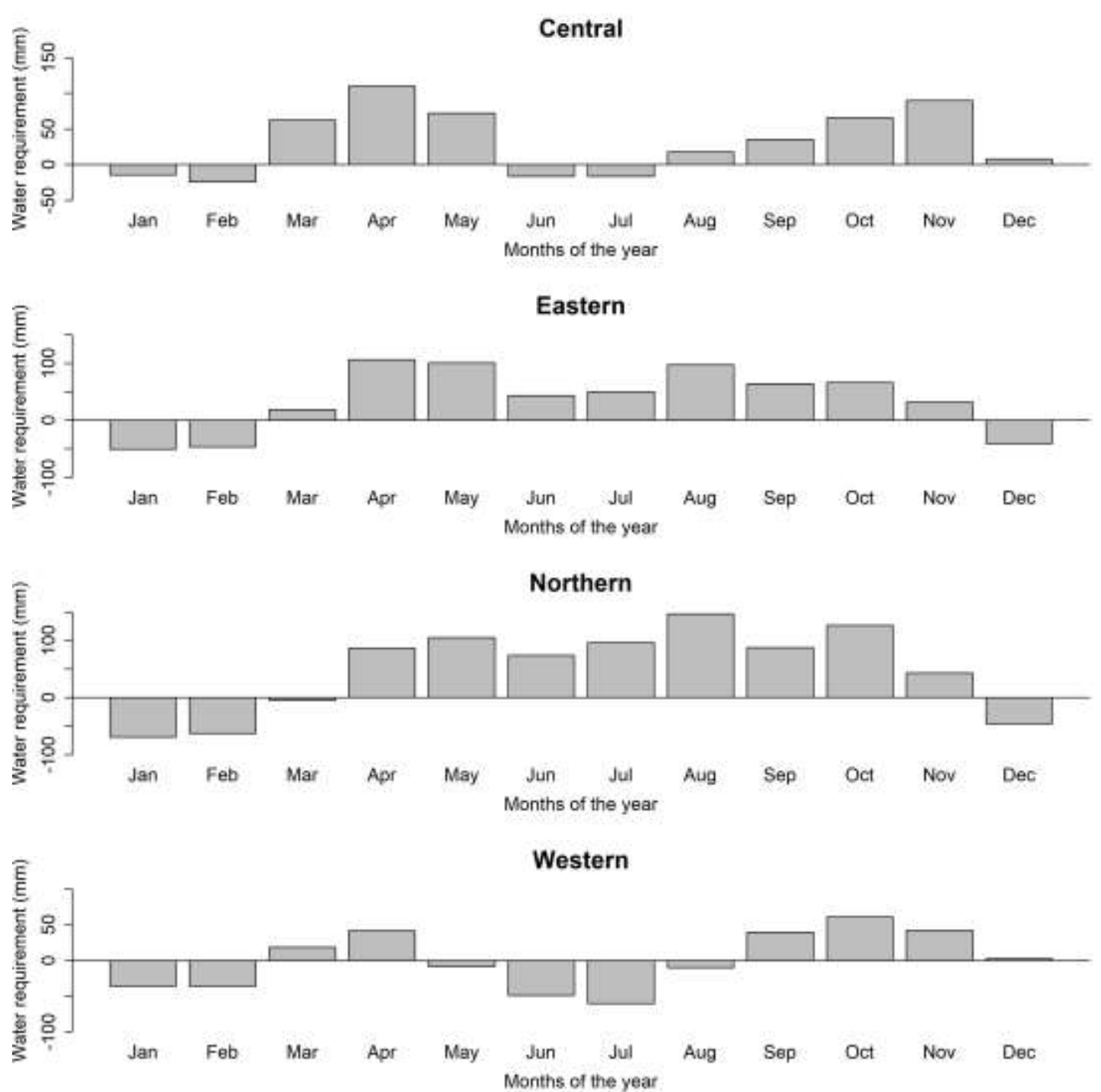

Figure 5. Monthly water requirement for rainfed ponds the different regions 